\title{
Clinton's and Trump's Positions on Major Healthcare Issues
}

As the presidential election nears, the positions of the two major candidates on healthcare have received more attention. Both Clinton and Trump have their healthcare positions listed on their websites $(1,2)$. Below is a table listing their positions from their websites and occasionally other sources followed by a brief discussion of each of the issues.

Table 1. Presidential candidate positions on healthcare issues. A questions mark denotes an unclear position.

\begin{tabular}{|l|c|c|}
\hline Issue & Clinton & Trump \\
\hline Affordable Care Act (ACA, Obamacare) & Pro & Con \\
\hline Access to reproductive health & Pro & $?$ \\
\hline Allow importing drugs to reduce costs & Pro & Pro \\
\hline Block-grant Medicaid to the states & $?$ & Pro \\
\hline Coverage of poor & Pro & Pro \\
\hline Healthcare for illegal immigrants & Pro & $?$ \\
\hline Healthcare savings accounts & $?$ & Pro \\
\hline Increase access to healthcare & Pro & $\times$ \\
\hline $\begin{array}{l}\text { Increase income tax deductions for } \\
\text { healthcare costs }\end{array}$ & Pro & Pro \\
\hline Price transparency & Pro & Pro \\
\hline Public option & Pro & $?$ \\
\hline Reduce copays and deductibles & Pro & $?$ \\
\hline Sell insurance across state lines & $?$ & Pro \\
\hline
\end{tabular}

Affordable Care Act (ACA, Obamacare)

This is a major difference between Clinton and Trump. Clinton favors its retention (1). Trump favors its repeal (2).

\section{Access to reproductive health}

Clinton supports reproductive preventive care, affordable contraception, and safe and legal abortion (1). Trump's position is unclear. He currently is pro-life but would not use Federal funds for abortion (2). Federal funding for abortions us is prohibited by law (3).

\section{Allow importing drugs to reduce costs}

Both candidates favor importation of prescription drugs to reduce prices $(1,2)$.

\section{Block-grant Medicaid to the states}

Trump favors block-grants asserting that "the state governments know their people best and can manage the administration of Medicaid far better without federal overhead" (2). This idea is not new with Congressional Republicans 
pushing for block-granting Medicaid at least since the 1990s (4) Clinton's position is unclear (1).

\section{Coverage of poor}

Both candidates favor universal healthcare including the poor $(1,2)$.

\section{Healthcare for illegal immigrants}

Clinton favors extending healthcare to families regardless of immigration status by allowing families to buy health insurance on the health exchanges (1). Trump's website notes that providing healthcare to illegal immigrants costs us some $\$ 11$ billion annually and he favors strict enforcement of the current immigration laws (2).

\section{Healthcare savings accounts}

Trump favors savings accounts which are permitted under the ACA but with restrictions $(2,5)$. Clinton's position is unclear.

Increase access to healthcare

Both candidates favor increased access to healthcare $(1,2)$.

Increase income tax deductions for healthcare costs

Both candidates favor increasing income tax deductions for healthcare costs but their plans are different $(1,2)$. Trump favors full deduction of health insurance premium payments from tax returns. Clinton favors a refundable tax credit of up to $\$ 5,000$ per family for excessive out-of-pocket costs.

\section{Price transparency}

Both candidates favor increased healthcare price transparency $(1,2)$.

\section{Public option}

Clinton favors a public option (1). Trump's position is unclear.

\section{Reduce copays and deductibles}

Clinton favors reducing copays and deductibles (1). Trump's position is unclear.

\section{Sell insurance across state lines}

Trump favors insurance companies selling healthcare insurance across state lines (2). This has been a part of the platform of every Republican presidential nominee and is permitted in 5 states but insurance companies have been reluctant to sell these policies (6). Clinton's position is unclear.

\section{References}

1. Hillary Clinton for America. Available at: https://www.hillaryclinton.com/issues/health-care/ (accessed 9/6/16). 
2. Donald J. Trump for President. Available at: https://www.donalditrump.com/positions/healthcare-reform (accessed 9/6/16).

3. Salganicoff A, Beamesderfer A, Kurani N, Sobel L. Coverage for abortion services and the ACA. Kaiser Family Foundation. September 19, 2014. Available at: http://kff.org/womens-health-policy/issue-brief/coverage-forabortion-services-and-the-acal (accessed 9/6/16).

4. Dickson V. GOP's Medicaid block-grant plan won't happen while Obama's in office. Medscape. March 19, 2015. Available at: http://www.modernhealthcare.com/article/20150319/NEWS/150319877 (accessed 9/6/16).

5. Norris L. Under the ACA, can I still have an individual HDHP and an HSA? Healthinsurance.org. May 16, 2016. Available at:

https://www.healthinsurance.org/faqs/i-have-an-individual-hdhp-and-an-hsawill-i-still-be-able-to-have-them-under-the-acal (accessed 9/6/16).

6. Cauchi R. Out-of-state health insurance - allowing purchases (state implementation report). National Conference of State Legislators. December, 2015. Available at: http://www.ncsl.org/research/health/out-of-state-healthinsurance-purchases.aspx (accessed 9/6/16). 